\title{
CHROMIUM TRICARBONYL $\eta^{6}$-COMPLEXES OF $\left(\eta^{5}\right.$-CYCLO- PENTADIENYL $)\left(\eta^{4}\right.$-TETRAPHENYLCYCLOBUTADIENE)COBALT
}

\author{
FUNG-F, HONG* and YUAN-TERNG CHANG
}

Department of Chemistry, National Chung-Hsing University, Taichung 40227, Taiwan, R.O.C.

\author{
and \\ MING-CHU CHENG and YU WANG \\ Department of Chemistry, National Taiwan University, Taipei 10764, Taiwan, R.O.C.
}

(Received 22 February 1993; accepted 2 April 1993)

\begin{abstract}
The reaction of ( $\eta^{5}$-cyclopentadienyl)( $\eta^{4}$-tetraphenylcyclobutadiene)cobalt (1) with excess $\mathrm{Cr}(\mathrm{CO})_{6}$ leads to four identified heterometallic compounds. They are compounds $2,3\left(3^{\prime}\right.$ and $\left.3^{\prime \prime}\right)$ and 4 with one, two, and three phenyl ring(s) being complexed with $\mathrm{Cr}(\mathrm{CO})_{3}$ fragment(s), respectively. Compounds $3^{\prime}$ and $\mathbf{3}^{\prime \prime}$ are two structural isomers with two arene $\mathrm{Cr}(\mathrm{CO})_{3}$ groups in the trans and cis positions, respectively. These compounds were characterized by mass, IR, E.A. and ${ }^{1} \mathrm{H}$ and ${ }^{13} \mathrm{C}$ NMR spectra. The $\mathrm{X}$-ray crystal structure of $3^{\prime}$ has been determined and can be regarded as three metals linked by three connected $\pi$-rings. It shows that two $\mathrm{Cr}(\mathrm{CO})_{3}$ complexed phenyl rings are about parallel to the cyclobutadiene ring which causes the downfield shift of the Cp signal of 3 ' in the ' $\mathrm{H}$ NMR spectrum. Steric effects are more important than electronic effects in $3^{\prime}$ in the interpretation of the geometry of the two arene $\mathrm{Cr}(\mathrm{CO})_{3}$ fragments.
\end{abstract}

The applications of arene $\mathrm{Cr}(\mathrm{CO})_{3}$ in organic synthesis are well known and numerous derivatives of arene $\mathrm{Cr}(\mathrm{CO})_{3}$ compounds have been made. ${ }^{1}$ However, examples of the synthesis of mixed-metal compounds through bridging $\pi$-rings are rare. ${ }^{2}$ We know that the heteronuclear metal complexes offer the chance to observe cooperative effects of the different metal centres when the metals are held in close proximity by bridging ligands. ${ }^{3}$ The cooperative effect should be enhanced through directly joined $\pi$-rings. Therefore, it was of interest to prepare this type of compound and examine their physical and chemical properties.

$\left(\eta^{5}\right.$-Cyclopentadienyl) $\left(\eta^{4}\right.$-tetraphenylcyclobutadiene)cobalt (1) is a sandwich-like compound with four phenyl rings attached to four carbons of the cyclobutadiene ring. It has four active sites, four phenyl groups, for metal $\pi$-complexation. The dihedral angle between each phenyl and the cyclo-

* Author to whom correspondence should be addressed. butadiene ring is around $50-60^{\circ} .^{4}$ It seems that the space between the phenyl rings is too small to accommodate any $\mathrm{Cr}(\mathrm{CO})_{3}$ fragment without significant structural change of 1 . It was therefore of interest to study the possibility of incorporating metal fragment(s) into phenyl rings and to monitor the structural change and effects caused. We now report the preparation of 2,3 ( $3^{\prime}$ and $3^{\prime \prime}$ ) and 4 and the crystal structure of $3^{\prime}$, which contains mixed metals through the directly joined $\pi$-rings.

\section{RESULTS AND DISCUSSION}

The reaction of 1 with $\mathrm{Cr}(\mathrm{CO})_{6}$ in dibutyl ether in the presence of a small amount of THF resulted in attachment of $\mathrm{Cr}(\mathrm{CO})_{3}$ fragments to the phenyl groups (Scheme 1).

The yields of $2,3^{\prime}, 3^{\prime \prime}$ and 4 are $44.2 \%, 14.0 \%$, $7.3 \%$ and $10.8 \%$, respectively. Compounds $3^{\prime}$ and 3" are structural isomers (Fig. 1). They are both orange and very close in $R_{f}$ values $\left(0.21\right.$ for $3^{\prime \prime}, 0.19$ 


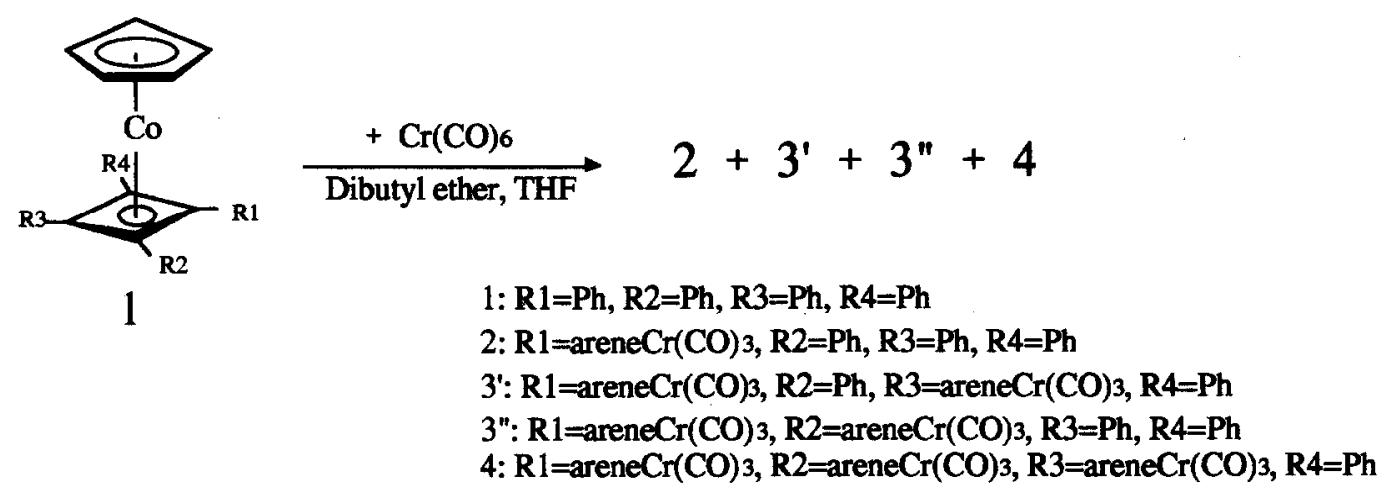

Scheme 1.

for $3^{\prime}$ in $\mathrm{CH}_{2} \mathrm{Cl}_{2} /$ hexanes = 1:1). A slight difference in solubilities makes the separation of these two isomers by CTLC possible ; $\mathbf{3}^{\prime \prime}$ was eluted first before $3^{\prime}$. The fact that the yield of $3^{\prime}$ is higher than $3^{\prime \prime}$ is reasonable from the viewpoint of steric effects.

Compound 3 ' was crystallized by diffusing $\mathrm{CH}_{2} \mathrm{Cl}_{2}$ from the solution to the toluene and dark red crystals were obtained. The crystal data of $\mathbf{3}^{\prime}$ shows that the dihedral angles between the $\mathrm{Cr}(\mathrm{CO})_{3}$ complexed phenyl rings and cyclobutadiene ring are around $10^{\circ}$ (Fig. 2 and Table 3 ). This is a significant structural change compared with that of 1 . The change in structure might help in releasing the tension between areneCr(CO) $)_{3}$ and non-complexed phenyl rings. Also, the downfield shift of the $\mathrm{Cp}$ in ${ }^{1} \mathrm{H}$ NMR from 4.63 in 1 to 4.89 in $3^{\prime}$ can be attributed to this structural change. It can be explained by a better overlap between the cyclobutadiene ring and the two $\mathrm{Cr}(\mathrm{CO})_{3}$ complexed phenyl rings through $\pi$-interaction (Fig. 3). By that process the two $\mathrm{Cr}(\mathrm{CO})_{3}$ complexed phenyl rings may donate more electron density to the electron-withdrawing cyclobutadiene ring and then to the $\mathrm{Cp}$ ring that causes the downfield shift. It is also supported by the fact that a sequential downfield shift from 2 to 3 to 4 with more $\mathrm{Cr}(\mathrm{CO})_{3}$ complexed 1 (2: 4.76, $3^{\prime}$ : $\left.4.89,3^{\prime \prime}: 4.93,4: 5.05\right)$. ${ }^{1} \mathrm{H}$ NMR also shows an obvious upfield shift for the phenyl ring(s) of arene$\mathrm{Cr}(\mathrm{CO})_{3}$ and the almost unaffected phenyl group(s) in the same molecule, which is consistent with the well-known observations. ${ }^{5}$

The two $\operatorname{Cr}(\mathrm{CO})_{3}$ fragments are pointed in different directions from the CoCp fragment in $\mathbf{3}^{\prime}$, which might avoid the repulsion between $\mathrm{Cr}(\mathrm{CO})_{3}$ and CoCp. The dihedral angle between cyclobutadiene and one of the non-complexed phenyls, $75.9^{\circ}$, is larger than that in 1 . This might also help to relieve the tension between the phenyl and the $\mathrm{Cr}(\mathrm{CO})_{3}$ fragment. The bond lengths of four cyclobutadiene carbon-carbon bonds in the planar cyclobutadiene ring is about the same, which is around $1.46 \AA$. The $\mathrm{Cp}$ and $\mathrm{C}_{4}$ rings are almost coplanar [dihedral angle $1.9^{\circ}$ ]. Compound $3^{\prime}$ can be regarded as three metal fragments that are linked

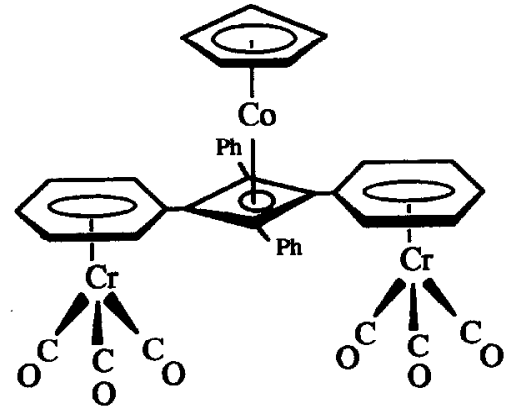

$3^{\prime}$

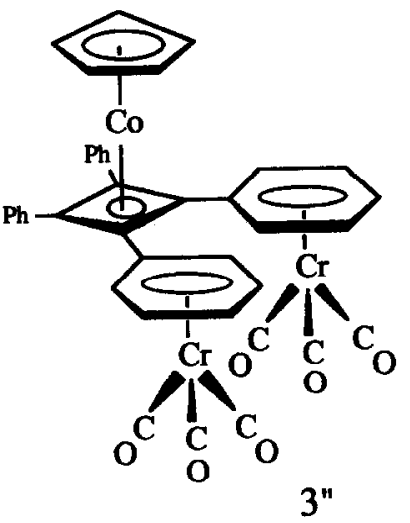

3"

Fig. 1. The isomeric structures of $3^{\prime}$ and $3^{\prime \prime}$. 


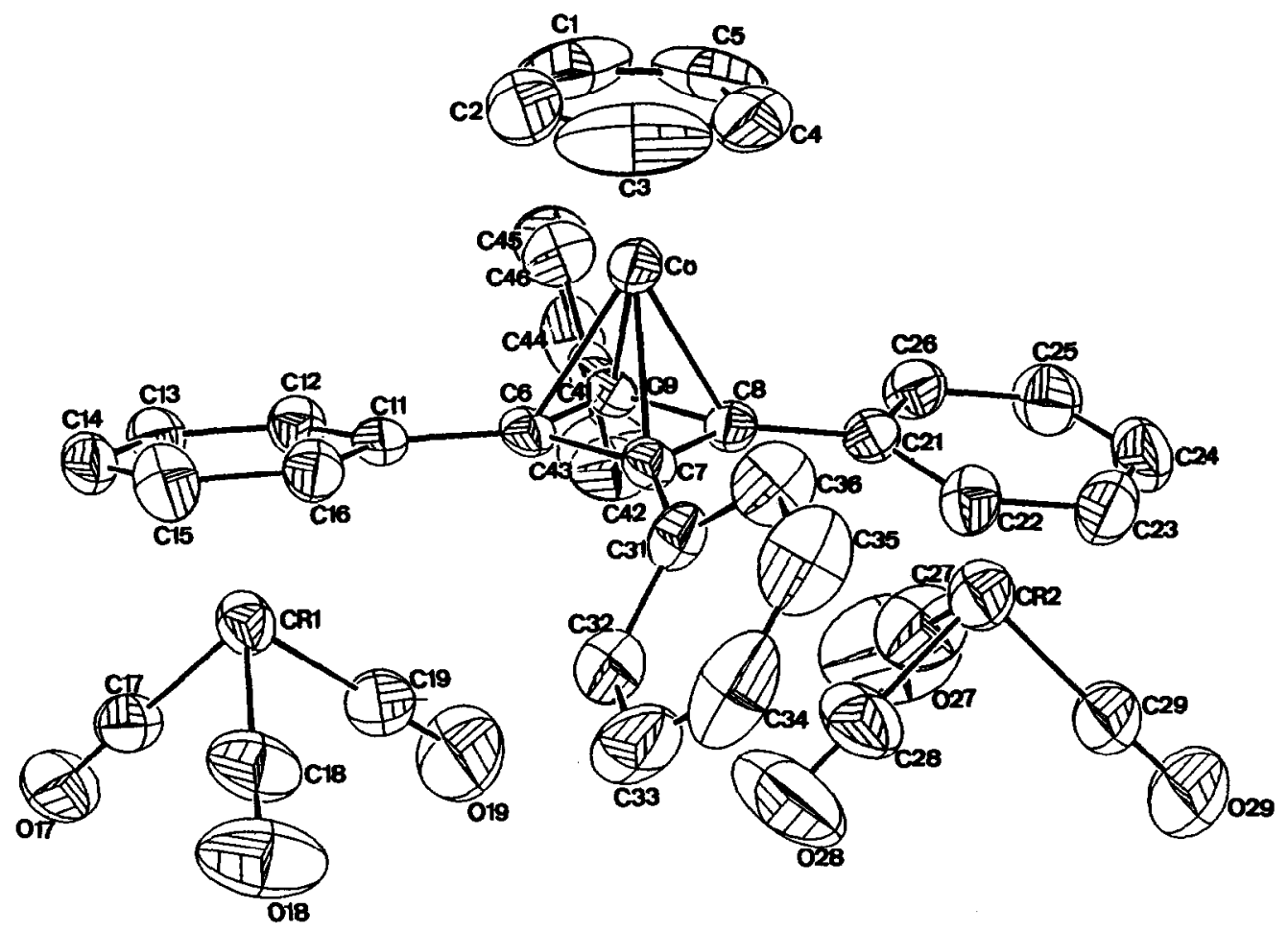

Fig. 2. ORTEP drawing with the numbering scheme for the non-hydrogen atoms of $\mathbf{3}^{\prime}$.

by a 6-4-6 conjugated $\pi-\pi$ ring system, which is rare according to the literature.

Hunter pointed out that the planarity of the arene ring can be distorted by a substituent. ${ }^{6}$ An inward distortion, $\delta d<0$, will take place when the substituent is an electron-withdrawing group. On the other hand, an outward distortion, $\delta d>0$, is expected for an electron-donating substituent. ${ }^{7}$ The above rule is obeyed unless a very bulky substituent is present. The cyclobutadiene ring is an electronwithdrawing group due to its tendency of aromaticity with six $\pi$-electrons. It is also supported by the fact that the positive values of $\Delta \pi$ in the ${ }^{13} \mathrm{C}$

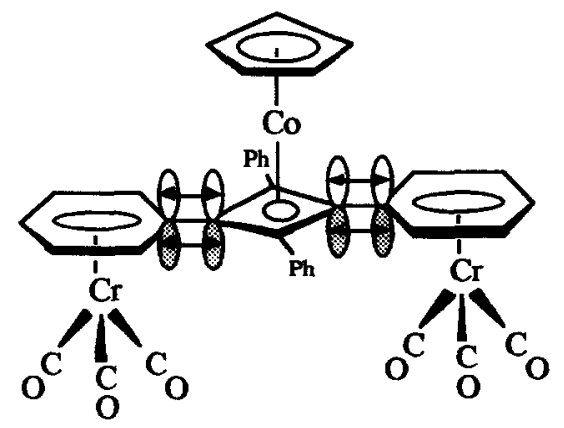

Fig. 3. The enhancement of interaction through the overlap of $p$-orbitals in the $\pi$-rings.
NMR spectrum of the $\eta^{6}$-complexed phenyl group (2.04 ppm for 2, $1.72 \mathrm{ppm}$ for $3^{\prime}, 1.66$ and $1.36 \mathrm{ppm}$ for $3^{\prime \prime}, 2.946,0.285$ and $0.294 \mathrm{ppm}$ for 4) were observed. According to Hunter, a positive $\Delta \pi$ in ${ }^{13} \mathrm{C}$ NMR indicates that the substituent, $\mathrm{a}_{4}$ ring, is an electron-withdrawing group. ${ }^{8}$ However, in our case a slightly outward distortion is observed, even though an electron-withdrawing group $\left(\mathrm{C}_{4}\right.$ ring $)$ is attached to the areneCr(CO) $)_{3}$ ring (Table 2). This opposite result to the above rule strongly suggests that the steric effect is more important than the electronic effect in this case. An inward distortion will not be favoured for the strong steric interaction between $\mathrm{Cr}(\mathrm{CO})_{3}$ and the rest of the molecular fragment.

The orientation of $\mathrm{Cr}(\mathrm{CO})_{3}$ in areneCr$(\mathrm{CO})_{3}$ has been the subject of extensive studies. An antieclipsed form is observed for areneCr(CO) $)_{3}$ with an electron-withdrawing substituent. On the other hand, a syn-eclipsed form is observed for arene$\mathrm{Cr}(\mathrm{CO})_{3}$ with an electron-donating substituent. ${ }^{9}$ However, it will be distorted to a nearly staggered structure when the substituent is very bulky. In the structure of (1'-t-butyl-2',2'-dimethylpropyl)- $\pi$ (tricarbonylchromium)benzene the chromium carbonyl group was found to eclipse $44^{\circ}$ away from its expected syn-eclipsed form due to its bulky substituent. ${ }^{10}$ It is about $30^{\circ}$ in $3^{\prime}$ for both arene- 


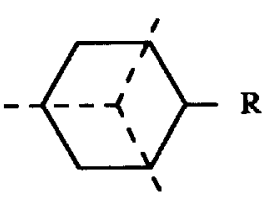

anti-eclipse

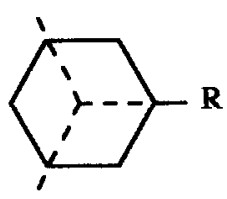

syn-eclipse

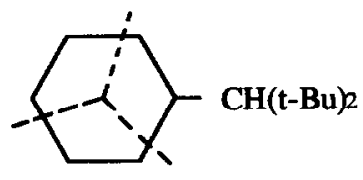

1'-t-butyl-2',2'-dimethylpropyl)- $\pi$ (tricarbonylchromium)benzene
$\mathrm{Cr}(\mathrm{CO})_{3}$ fragments. This result also supports the observation that areneCr(CO) ${ }_{3}$ is attached by a very bulky, even though electron-withdrawing, group in $\mathbf{3}^{\prime}$.

Compound 4 was obtained in a reasonable amount. It is interesting to find that three $\mathrm{Cr}(\mathrm{CO})_{3}$ fragments are able to insert into the already crowded area. In a related case Grimes was only able to place two $\mathrm{Cr}(\mathrm{CO})_{3}$ fragments into a carborane, nido-2,3- $\left(\mathrm{PhCH}_{2}\right)_{2} \mathrm{C}_{2} \mathrm{~B}_{4} \mathrm{H}_{6}$, even though four phenyl groups and more room are available in that compound. ${ }^{11}$

\section{EXPERIMENTAL}

\section{Preparation of $\left(\eta^{5}-\mathrm{C}_{5} \mathrm{H}_{5}\right)\left(\mathrm{PPh}_{3}\right) \mathrm{Co}\left(\mathrm{C}_{4} \mathrm{Ph}_{4}\right)$}

The synthesis of the title compound was patterned on the procedure in the literature. ${ }^{12}$

\section{Preparation of $1,\left(\eta^{5}-\mathrm{C}_{5} \mathrm{H}_{5}\right) \mathrm{Co}\left(\mathrm{C}_{4} \mathrm{Ph}_{4}\right)$}

By refluxing $\left(\eta^{5}-\mathrm{C}_{5} \mathrm{H}_{5}\right)\left(\mathrm{PPh}_{3}\right) \mathrm{Co}\left(\mathrm{C}_{4} \mathrm{Ph}_{4}\right)$ in toluene for $12 \mathrm{~h}$ one may obtain a quantitative yield of the title compound.

\section{Apparatus and materials}

All operations were performed in a nitrogenflushed glove-box or in a vacuum system. Freshly distilled solvents were used. All processes of separation of the products were performed by Centrifugal Thin Layer Chromtography (CTLC), Chromatotron, Harrison model 8924. ${ }^{1} \mathrm{H}$ and ${ }^{13} \mathrm{C}$ NMR spectra were recorded on a Varian- 300 spectrometer at 300 and $75.46 \mathrm{MHz}$, respectively. Chemical shifts are reported in ppm downfield from internal TMS. IR spectra were recorded in $\mathrm{CH}_{2} \mathrm{Cl}_{2}$ on a Hitachi 270-30. Mass spectra were recorded on a Joel JMS-SX/SX 102A GC/MS/MS. Elementary analyses were recorded on a Heraeus CHN-O-SRapid. X-ray diffraction data were collected on an Enraf-Nonius CAD4 diffractometer; the essential crystal data of $\mathbf{3}^{\prime}$ are given in Table 1 . Structure analyses are processed on a microvax computer using NRC VAX software. ${ }^{13}$

\section{Reaction of $\left(\eta^{5}-\mathrm{C}_{5} \mathrm{H}_{5}\right) \mathrm{Co}\left(\mathrm{C}_{4} \mathrm{Ph}_{4}\right)$ with $\mathrm{Cr}(\mathrm{CO})_{6}$}

Into a $250 \mathrm{~cm}^{3}$ round-bottom flask equipped with a condenser and a magnetic stirrer were placed $\left(\eta^{5}\right.$ $\left.\mathrm{C}_{5} \mathrm{H}_{5}\right) \mathrm{Co}\left(\mathrm{C}_{4} \mathrm{Ph}_{4}\right)(0.6 \mathrm{~g}, 1.24 \mathrm{mmol})$ and chromium hexacarbonyl $(2.74 \mathrm{~g}, 12.42 \mathrm{mmol})$. Anhydrous dibutyl ether $\left(120 \mathrm{~cm}^{3}\right)$ and anhydrous tetrahydrofuran (THF) $\left(12 \mathrm{~cm}^{3}\right)$ were added and the reaction mixture was refluxed under dry nitrogen for $36 \mathrm{~h}$. The reactor was cooled to room temperature and filtered and the solvent removed in vacuo.

The residue was dissolved in a small amount of $\mathrm{CH}_{2} \mathrm{Cl}_{2}$ and then was loaded onto CTLC for separation. Four bands were collected through the elution of a mixture of solvents. The ratio of solvent mixture $\left(\mathrm{CH}_{2} \mathrm{Cl}_{2} /\right.$ hexanes $)$ changed from $4: 1$ to

Table 1. Crystal data for $\mathbf{3}^{\prime}$

\begin{tabular}{ll}
\hline Formula & $\mathrm{C}_{39} \mathrm{H}_{25} \mathrm{O}_{6} \mathrm{Co}_{1} \mathrm{Cr}_{2}$ \\
Formula weight & 752.5481 \\
Diffractometer used & $\mathrm{CAD} 4$ \\
$a(\AA)$ & $13.765(6)$ \\
$b(\AA)$ & $16.765(14)$ \\
$c(\AA)$ & $28.841(7)$ \\
$V\left(\AA^{3}\right)$ & $6656(6)$ \\
$Z$ & 8 \\
$D_{\mathrm{c}}\left(\mathrm{g} \mathrm{cm}^{-3}\right)$ & 1.502 \\
Space group & Orthorhombic, Pbca \\
$F(000)$ & 3056 \\
$\left.\mu(\mathrm{cm})^{-1}\right)$ & 11.64 \\
Transmission & $0.97-1.0$ \\
$R^{a}$ & 0.042 \\
$R_{\mathrm{w}}{ }^{3}$ & 0.034 \\
$\mathrm{G} . \mathrm{O} . \mathrm{F}$. & 2.36 \\
Crystal size (Inm) & $0.2 \times 0.3 \times 0.25$ \\
$2 \theta_{\text {max }}\left({ }^{\circ}\right)$ & 45 \\
Temperature (K) & 298 \\
No. of reflections measured & 4321 \\
No. of observed reflections & 3013 \\
$(\Lambda / \sigma)_{\text {max }}$ & 0.071 \\
$(\Delta \rho)_{\text {max }}$ min $\left(\mathrm{e} \AA{ }^{-3}\right)$ & $0.5,-0.5$ \\
Second extinction coeff. & $2.2(2) \times 10^{-4}$ \\
\hline$-2 .-$ & \\
\hline
\end{tabular}

$$
\begin{aligned}
& { }^{a} R=\left[\Sigma \| F_{\mathrm{o}}|-| F_{\mathrm{c}}|/| F_{\mathrm{o}} \mid\right] . \\
& { }^{b} R_{\mathrm{w}}=\left[\Sigma \mathrm{w}\left(\left\|F_{\mathrm{o}}|-| F_{\mathrm{c}}\right\|^{2} / \Sigma \mathrm{w}\left(\left|F_{\mathrm{o}}\right|^{2}\right)^{1 / 2}\right] ; \mathrm{w}=1 / \sigma^{2} F_{\mathrm{o}} .\right.
\end{aligned}
$$


Table 2. Selected bond distances $(\AA)$ and angles $\left(^{\circ}\right)$

\begin{tabular}{|c|c|c|c|c|c|}
\hline $\mathrm{Co}-\mathrm{C}(1)$ & \multicolumn{2}{|c|}{$2.044(6)$} & $C r-C(17)$ & \multicolumn{2}{|c|}{$1.845(6)$} \\
\hline $\mathrm{Co}-\mathrm{C}(2)$ & \multicolumn{2}{|c|}{$2.037(6)$} & $\mathrm{Cr}-\mathrm{C}(18)$ & \multicolumn{2}{|c|}{$1.834(6)$} \\
\hline $\mathrm{Co}-\mathrm{C}(3)$ & \multicolumn{2}{|c|}{$2.027(6)$} & $\mathrm{Cr}-\mathrm{C}(19)$ & \multicolumn{2}{|c|}{$1.814(6)$} \\
\hline $\mathrm{Co}-\mathrm{C}(4)$ & \multicolumn{2}{|c|}{$2.012(6)$} & $\mathrm{Cr}(2)-\mathrm{C}(21)$ & \multicolumn{2}{|c|}{$2.258(5)$} \\
\hline $\mathrm{Co}-\mathrm{C}(5)$ & \multicolumn{2}{|c|}{$2.038(6)$} & $\mathrm{Cr}(2)-\mathrm{C}(22)$ & \multicolumn{2}{|c|}{$2.178(5)$} \\
\hline $\mathrm{Co}-\mathrm{C}(6)$ & \multicolumn{2}{|c|}{$1.979(5)$} & $\mathrm{Cr}(2)-\mathrm{C}(23)$ & \multicolumn{2}{|c|}{$2.180(6)$} \\
\hline $\mathrm{Co}-\mathrm{C}(7)$ & \multicolumn{2}{|c|}{$1.971(5)$} & $\mathrm{Cr}(2)-\mathrm{C}(24)$ & \multicolumn{2}{|c|}{$2.202(6)$} \\
\hline $\mathrm{Co}-\mathrm{C}(8)$ & \multicolumn{2}{|c|}{$1.974(5)$} & $\mathrm{Cr}(2)-\mathrm{C}(25)$ & \multicolumn{2}{|c|}{$2.210(7)$} \\
\hline $\mathrm{Co}-\mathrm{C}(9)$ & \multicolumn{2}{|c|}{$1.969(5)$} & $\mathrm{Cr}(2)-\mathrm{C}(26)$ & \multicolumn{2}{|c|}{$2.237(5)$} \\
\hline $\mathrm{Cr}-\mathrm{C}(11)$ & \multicolumn{2}{|c|}{$2.251(5)$} & $\mathrm{Cr}(2)-\mathrm{C}(27)$ & \multicolumn{2}{|c|}{$1.897(7)$} \\
\hline $\mathrm{Cr}-\mathrm{C}(12)$ & \multicolumn{2}{|c|}{$2.222(6)$} & $\mathrm{Cr}(2)-\mathrm{C}(28)$ & \multicolumn{2}{|c|}{$1.859(7)$} \\
\hline $\mathrm{Cr}-\mathrm{C}(13)$ & \multicolumn{2}{|c|}{$2.215(5)$} & $\mathrm{Cr}(2)-\mathrm{C}(29)$ & \multicolumn{2}{|c|}{$1.821(6)$} \\
\hline $\mathrm{Cr}-\mathrm{C}(14)$ & \multicolumn{2}{|c|}{$2.217(5)$} & $C(6)-C(7)$ & \multicolumn{2}{|c|}{$1.461(7)$} \\
\hline $\mathrm{Cr}-\mathrm{C}(15)$ & \multicolumn{2}{|c|}{$2.211(5)$} & $C(6)-C(9)$ & \multicolumn{2}{|c|}{$1.454(7)$} \\
\hline $\mathrm{Cr}-\mathrm{C}(16)$ & \multicolumn{2}{|c|}{$2.215(5)$} & $C(7)-C(8)$ & \multicolumn{2}{|c|}{$1.456(7)$} \\
\hline $\mathrm{C}(6)-\mathrm{Co}-$ & & $43.39(21)$ & $\mathrm{C}(6)-\mathrm{Co}-\mathrm{C}$ & & $62.26(21)$ \\
\hline $\mathrm{C}(6)-\mathrm{Co}-$ & & $43.23(21)$ & $\mathrm{C}(7)-\mathrm{Co}-\mathrm{C}$ & & $43.32(21)$ \\
\hline $\mathrm{C}(7)-\mathrm{Co}-$ & & $63.44(22)$ & $\mathrm{C}(8)-\mathrm{Co}-\mathrm{C}$ & & $43.14(21)$ \\
\hline $\mathrm{C}(17)-\mathrm{Cr}-$ & & $89.4(3)$ & $\mathrm{C}(17)-\mathrm{Cr}-\mathrm{C}$ & & $86.9(3)$ \\
\hline $\mathrm{C}(18)-\mathrm{Cr}-$ & & $89.4(3)$ & $\mathrm{C}(27)-\mathrm{Cr}(2)$ & (28) & $87.6(3)$ \\
\hline $\mathrm{C}(27)-\mathrm{Cr}(2$ & (29) & $87.8(3)$ & $\mathrm{C}(28)-\mathrm{Cr}(2)$ & (29) & $92.3(3)$ \\
\hline$C(7)-C(6)-$ & & $90.6(4)$ & $C(7)-C(6)$ & & $136.2(5)$ \\
\hline $\mathrm{C}(9)-\mathrm{C}(6)-$ & & $133.2(5)$ & $C(6)-C(7)-$ & & $89.0(4)$ \\
\hline $\mathrm{C}(6)-\mathrm{C}(7)-$ & & $135.0(5)$ & $\mathrm{C}(8)-\mathrm{C}(7)$ & & $134.8(5)$ \\
\hline$C(7)-C(8)$ & & $91.0(4)$ & $\mathrm{C}(7)-\mathrm{C}(8)$ & & $135.2(5)$ \\
\hline$C(9)-C(8)-$ & & $133.4(5)$ & $C(6)-C(9)-$ & & $89.5(4)$ \\
\hline$C(6)-C(9)$ & & $135.8(5)$ & $C(8)-C(9)-$ & & $132.2(5)$ \\
\hline $\mathrm{Cr}-\mathrm{C}(17)-$ & & $178.0(5)$ & $\mathrm{Cr}-\mathrm{C}(18)-\mathrm{C}$ & & $178.6(5)$ \\
\hline $\mathrm{Cr}-\mathrm{C}(19)-$ & & $178.1(6)$ & $\mathrm{Cr}(2)-\mathrm{C}(27)$ & (27) & $177.8(7)$ \\
\hline $\mathrm{Cr}(2)-\mathrm{C}(28$ & $(28)$ & $176.5(7)$ & $\mathrm{Cr}(2)-\mathrm{C}(29)$ & (29) & $177.9(7)$ \\
\hline
\end{tabular}

$1: 1$ as the separation proceeded. The first yellow band, $R_{f}(0.66)$ in $1: 1$ of $\mathrm{CH}_{2} \mathrm{Cl}_{2}$-hexanes, was identified as a small amount of unreacted 1. Compound 2 , orange $\left(R_{f}=0.42\right)$, was collected as the second band. The third band contains $3^{\prime}$ and $3^{\prime \prime}$. Both are orange and are very close in $R_{f} \mathrm{~s} ; 0.21$ for $3^{\prime \prime}$ and 0.19 for $3^{\prime}$. This mixture was separated further by CTLC with a slow solvent injection speed. Compound $3^{\prime \prime}$ was eluted out before $3^{\prime}$. Compound 4 , orange $\left(R_{f}=0.08\right)$, was collected as the last band. The separation in CTLC was under nitrogen.

2. ${ }^{1} \mathrm{H}$ NMR $\left(\mathrm{CDCl}_{3}\right): \delta 4.76(\mathrm{~s}, 5 \mathrm{H}, \mathrm{Cp}), 5.16$ $\left(\mathrm{m}, 1 \mathrm{H}, p-\mathrm{C}_{6} \mathrm{H}_{5}\right), 5.22\left(\mathrm{~m}, 2 \mathrm{H}, o-\mathrm{C}_{6} \mathrm{H}_{5}\right), 5.28(\mathrm{~m}$, $\left.2 \mathrm{H}, m-\mathrm{C}_{6} \mathrm{H}_{5}\right), 7.13(\mathrm{~m}, 5 \mathrm{H}$, phenyl), $7.39(\mathrm{~m}, 6 \mathrm{H}$, phenyl), 7.81 (m, 4H, phenyl). ${ }^{13} \mathrm{C}$ NMR $\left(\mathrm{CDCl}_{3}\right)::^{14} \delta 83.022(5 \mathrm{C}, \mathrm{Cp}), 90.023$ (1C, C11), 90.751 (2C: C13, C15), 92.790 (3C : C12, Cl4, C16), 110.783 (1C, C6), 126.388 (1C, C21), 128.107 (3C: C22, C24, C26), 127.398 (2C: C23, C25), 127.505 (2C: C31, C41), 128.320 (4C: C33, C35, C43, C45), 130.709 (6C: C32, C34, C36, C42, C44, C46),
134.486 (2C: C7, C9), 135.758 (1C, C8), 233.571 (3C, CO). IR $\left(\mathrm{CH}_{2} \mathrm{Cl}_{2}\right): v(\mathrm{CO}) 1966,1888 \mathrm{~cm}^{-1}$. Mass spectrum : $m / z 616\left(\mathrm{P}^{+}\right)$.

$3^{\prime} .{ }^{1} \mathrm{H}$ NMR $\left(\mathrm{CDCl}_{3}\right): \delta 4.89(\mathrm{~s}, 5 \mathrm{H}, \mathrm{Cp}), 5.11$ (m, 10H, phenyl), 7.51 (m, 6H, phenyl), $7.97(\mathrm{~m}$, $4 \mathrm{H}$, phenyl). ${ }^{13} \mathrm{C} \mathrm{NMR}\left(\mathrm{CDCl}_{3}\right): \delta 82.866(5 \mathrm{C}, \mathrm{Cp})$, 90.138 (2C: C11, C21), 90.325 (4C, C13, C15, C23, $\mathrm{C} 25), 92.052$ (6C: $\mathrm{C} 12, \mathrm{C} 14, \mathrm{C} 16, \mathrm{C} 22, \mathrm{C} 24, \mathrm{C} 26)$, 107.887 (2C: C6, C8), 128.324 (2C: C31, C41), 128.715 (4C: C33, C35, C43, C45), 131.430 (6C: $\mathrm{C} 32, \mathrm{C} 34, \mathrm{C} 36, \mathrm{C} 42, \mathrm{C} 44, \mathrm{C} 46), 132.908$ (2C: C7, C9), 233.117 (6C, CO). IR( $\left.\mathrm{CH}_{2} \mathrm{Cl}_{2}\right): v(\mathrm{CO}) 1974$, $1890 \mathrm{~cm}^{-1}$. Mass spectrum: $m / z 752\left(\mathrm{P}^{+}\right)$. Found: C, 62.1 ; H, 3.6. Calc. : C, $62.24 ; \mathrm{H}, 3.3 \%$.

$3^{\prime \prime}$. 'H NMR $\left(\mathrm{CDCl}_{3}\right): \delta 4.93(\mathrm{~s}, 5 \mathrm{H}, \mathrm{Cp}), 5.40$ $(\mathrm{m}, 6 \mathrm{H}), 5.69(\mathrm{~m}, 2 \mathrm{H}), 5.93(\mathrm{~m}, 2 \mathrm{H}), 7.27(\mathrm{~m}, 6 \mathrm{H})$, $7.45(\mathrm{~m}, 4 \mathrm{H}) \cdot{ }^{13} \mathrm{C}$ NMR $\left(\mathrm{CDCl}_{3}\right): \delta 83.313(5 \mathrm{C}$, Cp), 90.754 (1C, C31), 91.368 (2C: C33, C35), 92.178 (1C, C11), 92.285 (2C: C13, C15), 93.024 (3C: C32, C34, C36), 93.647 (3C: C12, C14, C16), 108.361 (2C: C6, C7), 127.427 (2C: C21, C41), 128.353 (4C: C23, C25, C43, C45), 129.688 (6C: 
Table 3. Dihedral angle between planes A and B

\begin{tabular}{llc}
\hline A & B & Angle ( ) \\
\hline 1 & 2 & $1.9(3)$ \\
1 & 3 & $10.46(25)$ \\
1 & 4 & $9.3(3)$ \\
1 & 5 & $53.3(3)$ \\
1 & 6 & $104.1(3)$ \\
2 & 3 & $12.2(3)$ \\
2 & 4 & $8.1(3)$ \\
2 & 5 & $52.9(3)$ \\
2 & 6 & $104.0(3)$ \\
3 & 4 & $19.47(20)$ \\
3 & 5 & $51.57(21)$ \\
3 & 6 & $99.95(20)$ \\
4 & 5 & $58.77(22)$ \\
4 & 6 & $110.30(21)$ \\
5 & 6 & $51.56(22)$ \\
\hline
\end{tabular}

Plane 1 : $\mathrm{C}(1)-\mathrm{C}(5)$; plane 2 : $\mathrm{C}(6)-\mathrm{C}(9)$; plane 3 : $\mathrm{C}(11)-\mathrm{C}(16)$; plane $4: \mathrm{C}(21)-\mathrm{C}(26)$; plane $5: \mathrm{C}(31)-$ $\mathrm{C}(36)$; plane $6: \mathrm{C}(41)-\mathrm{C}(46)$.

$\mathrm{C} 22, \mathrm{C} 24, \mathrm{C} 26, \mathrm{C} 42, \mathrm{C} 44, \mathrm{C} 46), 130.738$ (2C: C8, C9), 233.057 (6C, CO). IR $\left(\mathrm{CH}_{2} \mathrm{Cl}_{2}\right): v(\mathrm{CO}) 1970$, $1892 \mathrm{~cm}^{-1}$. Mass spectrum : $m / z 752\left(\mathrm{P}^{+}\right)$.

4. ${ }^{1} \mathrm{H}$ NMR $\left(\mathrm{CDCl}_{3}\right): \delta 5.05(\mathrm{~s}, 5 \mathrm{H}, \mathrm{Cp}), 5.19$ $(\mathrm{m}, 5 \mathrm{H}), 5.26(\mathrm{~m}, 3 \mathrm{H}), 5.50(\mathrm{~m}, 3 \mathrm{H}), 5.73(\mathrm{~m}, 2 \mathrm{H})$, $5.99(\mathrm{~m}, 2 \mathrm{H}), 7.45(\mathrm{~m}, 3 \mathrm{H}), 7.80(\mathrm{~m}, 2 \mathrm{H}) .{ }^{13} \mathrm{C} \mathrm{NMR}$ $\left(\mathrm{CDCl}_{3}\right): \delta 83.266(5 \mathrm{C}, \mathrm{Cp}), 91.312(2 \mathrm{C}: \mathrm{C} 11, \mathrm{C} 21)$, 91.624 (2C: C13, C15), 91.722 (2C: C23, C25), 91.918 (3C: C12, C14, C16), 92.007 (3C: C22, C24, C26), 92.113 (1C, C31), 92.585 (2C: C33, C35), 95.531 (3C: C32, C34, C36), 105.803 (2C: C6, C8), 106.142 (1C, C7), 128.581 (1C, C41), 128.786 (2C: C43, C45), 131.305 (3C: C42, C44, C46), 131.519 (1C, C9), $232.502(3 \mathrm{C}, \mathrm{CO}), 232.867$ (6C, CO). IR $\left(\mathrm{CH}_{2} \mathrm{Cl}_{2}\right): v(\mathrm{CO}) 1974,1894 \mathrm{~cm}^{-1}$. Mass spectrum : $m / z 888\left(\mathrm{P}^{+}\right)$.

Supplementary material available. Tables of atomic coordinates and thermal parameters, bond lengths and angles, anisotropic thermal parameters and hydrogen atom coordinates for $\mathbf{3}^{\prime}$.

Acknowledgement - Financial support of the National Research Councils of the R.O.C. under Grant NSC-820208-M-005-022 is gratefully acknowledged.

\section{REFERENCES}

1. (a) J. P. Collman, L. S. Hegedus, J. R. Norton and R. G. Finke, Principles and Applications of Organotransition Metal Chemistry. University Science Books, Mill Valley, CA (1987); (b) R. Davis and L. A. P. Kane-Maguire, Comprehensive Organometallic Chemistry (Edited by G. Wilkinson, F. G. A. Stone and E. W. Abel), Vol. 3, p. 953. Pergamon Press,
Oxford (1982) and refs therein; (c) W. E. Watts, Comprehensive Organometallic Chemistry (Edited by G. Wilkinson, F. G. A. Stone and E. W. Abel), Vol. 8, p. 1013. Pergamon Press, Oxford (1982); (d) H. M. Colquhoun, J. Holton, D. J. Thompson and M. V. Twigg, New Pathways for Organic Synthesis: Practical Applications of Transition Metals. Plenum Press, New York (1984); (e) E. P. Kundig, N. P. Do Thi, P. Paglia, D. P. Simmons, S. Spichiger and E. Wenger, Organometallics in Organic Synthesis (Edited hy A. de Meijere and T. Dieck), Vol. 1. Springer-Verlag, Berlin, Heidelberg (1988); (f) K. Schlogl, Organometallics in Organic Synthesis (Edited by A. de Meijere and T. Dieck), Vol. 2. Springer-Verlag, Berlin, Heidelberg (1988).

2. Ferrocenylphenyl chromium tricarbonyl, $\mathrm{Cp}_{2} \mathrm{Fe}-$ areneCr(CO $)_{3}$, has two $\pi$-rings ( $\mathrm{Cp}$ and arene) which are joined directly. (a) S. P. Gubin and V. S. Khandkarova, J. Organomet. Chem. 1970, 22, 449. Examples of the synthesis of homonuclear compounds through bridging $\pi$-rings are few. (b) L. D. Schulte and R. D. Rieke, J. Org. Chem. 1987, 52, 4829; (c) E. W. Neuse, J. Organomet. Chem. 1972, 40, 387.

3. (a) D. A. Roberts and G. L. Geoffroy, Comprehensive Organometallic Chemistry (Edited by G. Wilkinson, F. G. A. Stone and E. W. Abel), Ch. 40. Pergamon Press, Oxford (1982); (b) R. M. Bullock and C. P. Casey, Accts Chem. Res. 1987, $20,167$.

4. The crystal structure of $\mathbf{1}$ is not available; however, the structure of a closely related compound, $\mathrm{CpCo}\left(\mathrm{C}_{4} \mathrm{Ph}_{4} \mathrm{BH}\right)$, is known. (a) F.-E. Hong, C. W. Eigenbrot and T. P. Fehlner, J. Am. Chem. Soc. $1989,111,949$. The dihedral angle of another closely related compound, $\mathrm{Fe}(\mathrm{CO})_{3}\left(\mathrm{C}_{4} \mathrm{Ph}_{4}\right)$, is relatively smaller. (b) R. P. Dodge and V. Schomaker, Acta Cryst. 1965, 18, 614.

5. (a) R. V. Emanuel and E. W. Randall, J. Chem. Soc. $A$ 1969, 3002; (b) M. J. McGlinchey and T. S. Tan, Can. J. Chem. 1974, 52, 2439 ; (c) M. J. McGlinchey and J. L. Fletcher, Can. J. Chem. 1975, 53, 1525; (d) C. S. Keller, Tetrahedron Lett. 1978, 2361.

6. (a) A. D. Hunter, L. Shilliday, W. S. Furey and M. J. Zaworotko, Organometallics 1992, 11, 1550 ; (b) J. Li, A. D. Hunter, R. McDonald, B. D. Santarsiero, S. G. Bott and J. L. Atwood, Organometallics 1992, 11, 3050 .

7. The parameter $\delta d$ is defined as the difference between the $\mathrm{Cr}-\mathrm{C}_{i p s o}$ bond length and the average of the other $\mathrm{Cr}-\mathrm{C}(\mathrm{H})$ bond lengths. $\delta d=d \mathrm{Cr}-\mathrm{C}_{i p s o}-$ $d \mathrm{Cr}-\mathrm{C}(\mathrm{H})_{\mathrm{av}}$.

8. The $\Delta \pi$ is defined as the difference (in ppm) between the measured chemical shifts of the para- and metasubstituted carbon atoms in the mono-substituted complexes. $\Delta \pi=\delta_{\text {para }}-\delta_{\text {meta }}$. A. D. Hunter, L. Shilliday, W. S. Furey and M. J. Zaworotko, Organometallics $1992,11,1550$.

9. (a) T. A. Albright and B. K. Carpenter, Inorg. Chem. 1980, 19, 3092; (b) T. A. Albright, P. Hofmann and R. Hoffmann, J. Am. Chem. Soc. 1977, 99, 7546.

10. (a) F. van Meurs and H. van Konigsveld, J. Organomet. Chem. 1974, 78, 229; (b) F. van Meurs and H. 
van Konigsveld, J. Organomet. Chem. 1976, 118, 12. H. Yamazaki and Y. Wakatsui, J. Organomet. Chem. 295. 1977, 139, 157.

11. (a) T. Whelan, J. T. Spencer, M. R. Pourian and R. N. Grimes, Inorg. Chem. 1987, 26, 3116; (b) J. T. Spencer, M. R. Pourian, R. J. Butcher, E. Sinn and R. N. Grimes, Organometallics 1987, 6, 335 .

13. E. J. Gabe, Y. LePage, J.-P. Charland and F. L. Lee, J. Appl. Cryst. 1989, $22,384$.

14. All the ${ }^{13} \mathrm{C}$ NMR labelling of carbon atoms are referred to the labelling on crystal structure $3^{\prime}$. 